\author{
Aleksandra Kowalewska-Buraczewska \\ University of Białystok \\ e-mail: a.kowalewska@uwb.edu.pl \\ ORCID: 0000-0002-4601-2512
}

\title{
THE LOGIC AND NORMATIVE FORCE OF DUAL-CHARACTER GENERICS: \\ TOWARDS A THEORETICAL MODEL FOR THE STUDY OF NORMATIVELY SHIFTED PREDICATIONS
}

\begin{abstract}
This paper investigates the relationship between generic statements and the expression, transmission and persistence of social norms. The author presents the concept of normativity and its importance in the decision-making process in the context of social reality and social norms that comprise it (Bicchieri, 2006, 2016; Bicchieri et al., 2018). The paper analyses the idea of "what is normal" (Haslanger, 2014) to show how social norms are triggered by particular generic constructions relating to "social kinds", represented by noun phrases denoting "dual character concepts" (Knobe et al., 2013; Prasada et al., 2013; Leslie, 2015). DCCs are shown as effectively serving their persuasive and explanatory function due to their polysemous nature (Leslie, 2015) rather than to different pragmatics (Leslie, forthcoming). Special focus is placed on gender terms as particularly salient social kinds; this salience can be explained by a culturally pivotal role of social constructs of manhood and womanhood and by linguistic potential of generics in the development of social beliefs and legitimizing norm-driven behaviours.
\end{abstract}

Keywords: generics, normativity, social norms, gender terms, normative generics.

\section{Introduction}

Normativity has already been widely discussed within legal, social, psychological, and philosophical sciences as pertaining to the domain of statutory and non-statutory obligations, moral values, social beliefs, and standards of behaviour. The fact that agents should know and comply with them is a sine qua non for satisfying the basic need of being accepted as a member of a social group (belongingness) ${ }^{1}$. Norms, whether they are legal, social, or moral standards, are perceived as regulative tools for social category membership. 


\section{Aleksandra Kowalewska-Buraczewska}

Both legal and non-legal (cognitive, moral, aesthetic, social, or cultural) norms govern objects and phenomena that belong to human rather than natural categories ${ }^{2}$. Legal norms are characterized by a fixed and transparent linguistic make-up and logical form; they have an overt disposition and explicit sanction. Non-legal norms (i.e., cultural, moral, social, etc.), on the other hand, may be communicated with a variety of differently structured utterances whose language is not formulaic, and as such may not explicitly signal their normative force. It is assumed that in everyday communication, speakers use formally diverse constructions carrying social norms; such constructions operate as normative senses (normatively shifted predications) behind generics that relate to kinds that are important components of the social world.

Normative generics have long been noted in the literature (e.g. BurtonRoberts, 1977; Carlson, 1995, 2009; Lawler, 1973). The present paper draws on the most recent research on the topic (Haslanger 2010, 2014; Leslie 2014, $2015,2017)$ and attempts to propose a theoretical model for the empirical study of normative generalizations about social kinds (NG) that exhibit a distinctive property of dual conception (DCC).

The theoretical model is based on the following initial assumptions:

1. Certain social norms (i.e., norms structuring social scripts of roles attributed to social kinds with associated conceptual ideals) are carried by the normative senses of generic statements, where the subject NP is represented by a dual character concept (i.e., a concept allowing normative and descriptive interpretation). Normative reading is thus identified with the ideal that descriptive members of the kind need to fulfill, rather than with the descriptive criteria of kind membership;

2. Dual conception and the resulting polysemy characterize only those social kinds that are connoted as "salient, culturally important or charged" (Leslie, 2015; Haslanger, 2014). The ideal of a kind is determined by primary social roles that are attributed to such social kinds. Primary social roles are culture-specific and may be time-based;

3. As with principled generics, a generic name functioning as the sub-

ject of a normative generic statement takes the form of either an indefinite (bare) plural generic NP or an indefinite singular generic NP. The latter case seems more common when a generic name is modified by qualifiers such as true, real, or good (Leslie, 2015), or in negated/interrogative constructions challenging category membership in terms of normative rather than descriptive criteria.

The research to be based on the model under discussion focuses on the question of whether norms that are articulated in the form of a normative 
generic expressing some desirable regularity about a particular social kind (e.g. institution, process, role of kind of being), may in ordinary language be invoked and recognized by agents via different "normatively shifted predications" whose normative force may depend on social, cultural, historical and situational context. For practical reasons, the scope of social kinds under analysis will be narrowed down to gender terms and norms governing the social constructs of femininity/womanhood and masculinity/manhood that are present in ordinary language.

\section{Social norms and social cognition - why do people feel they should behave like others?}

Social norm is a broad term that covers a variety of conceptual issues that fall beyond the scope of this study, and so does an array of approaches represented in the literature. For simplicity, this study adopts the most general "functionalist" view of the topic, where social norms are conceived of as kind of "social grammar" whose rules specify what is acceptable and what is not in a society or group. The problem of why and how norms emerge and are accepted by agents ought to be discussed to show that if language is constitutive of social reality, it is naturally permeated by social rules in everyday interactions between individuals.

According to Brennan, Eriksson, Goodin and Southwood (2013), norms hold people responsible to each other for adherence to their common principles. In this, social norms place people in positions where they may praise or blame others for their behaviours and attitudes. The social meaning of norm-driven behaviours arises from the fact that their acceptability represents shared values, shared knowledge and shared expectations about what should and should not be done in certain social situations. In order for a social norm to govern a social practice, the norm has to exist; it has to be generally known that the normative rule is generally accepted and that people believe its normative rule applies (Brennan et al., 2013, pp. 2-4, 172). Following this logic, social norms are generally known as normative beliefs. However, a phenomenon known as pluralistic ignorance (Prentice \& Miller, 1993) reveals that a social norm can exist in the absence of a normative belief based on acceptance, as with norm-driven behaviours of people who believe that they are supposed to act in a certain way, but not that they ought to (i.e., that there are other people who expect them to conform to a certain rule, and that a refusal to conform will result in social sanctions such as exclusion). This can be explained in terms 


\section{Aleksandra Kowalewska-Buraczewska}

of a "normative-expectations view", according to which social norms, in order to exist, neither must be accepted by relevant individuals, nor do those individuals need to know that their attitude is shared by others. All that is needed is a normative expectation that others believe that a certain rule applies. This concept of social norm has been developed by Bicchieri (2006, p. $11 ; 2016$, p. 12), who explains the existence of social norms in terms of preferences. This means that a prerequisite for the existence and efficiency of a social norm is that a sufficiently large number of its followers or agents believe there are enough others who in fact conform. Moreover, Bicchieri (2006) argued that when social norms are perceived as legitimate, people believe that there must be strong arguments for a norm to be in place and feel motivated to conform to it. Thus, perceived legitimacy would be a matter of justified normative expectations. She claimed that according to the normative-beliefs view, social norms are self-justifying, and that any such norm tends to be perceived as legitimate. As is revealed by the pluralistic ignorance phenomenon, this does not always hold true. On the other hand, in the normative-expectations view, legitimacy is a matter of justified normative expectations. Thus, an individual who perceives a normative expectation as justified is likely to develop a justifiable normative belief, and consequently to perceive a norm as legitimate. A belief can only be justified if its corresponding normative expectations are justified.

\section{Genericity, normality, normalcy: What do people call "normal"?}

Social norms affect human behaviour, but their normative function is activated in communication. Norms are formulated and transmitted in and via language and persist in discursive space, even if many of them are harmful or inefficient (e.g. discriminatory norms against women and minorities), or fail to accommodate new cases due to having become so rigid that they encourage constructs that convey social stereotypes. The lexical terms norm, normativity, and normalcy all connote the idea of what is normal. Normal means 'conforming to a type, standard, or regular pattern' and 'according with, constituting, or not deviating from a norm, rule, or principle; interestingly, it also means 'occurring naturally', in which it is close to 'natural'3. Adjectival synonyms of normal, according to the Merriam-Webster dictionary, have the following readings:

- regular, normal, typical, natural mean 'being of the sort or kind that is expected as usual, ordinary, or average'. 
- regular stresses conformity to a rule, standard, or pattern (the club's regular monthly meeting).

- normal implies lack of deviation from what has been discovered or established as the most usual or expected (normal behaviour for a twoyear-old)

- typical implies showing all important traits of a type, class, or group and may suggest lack of strong individuality (a typical small town)

- natural applies to what conforms to a thing's essential nature, function, or mode of being (the natural love of a mother for her child) 4 .

In her research on generics and ideology, Haslanger ${ }^{5}$ observes that normal has two different senses: statistical and normative. In the statistical sense, the normal is what is statistically probable and refers to what things tend to be, whereas the normative sense refers to how things ought to be. In the context of social norms, the "normatively normal" 6 supports a normative claim: women ought to stay home with their babies because it is in the nature of things when circumstances are favourable (Haslanger, 2014, pp. 366-367). In this sense, the normative concept of "normal" draws on the historical concept of "essence". The "statistically normal", on the other hand, is what is statistically probable or regular. In either case, the background assumption behind these ideas is that what is unnatural or abnormal should be avoided, while what is normal (in the sense of how things ought to be) is valued as good and has to be protected, even when this means to improve on what is natural 7 .

\section{Generic generalizations and normative generics}

\subsection{Generic statements}

Generic generalizations are sentences whose subject NP refers to a kind of thing rather than to any individual object, and whose predicate expresses a general, regular property attributed to that kind ${ }^{8}$. Generics are complicated both psychologically and linguistically, and there is still little agreement about full analysis and a complete account. The approach adopted in this paper is thus a conceptual account of generics proposed by SarahJane Leslie ${ }^{9}$. In her voluminous research on generics, Leslie suggested that generalizing is a very primitive cognitive mechanism of sorting the world into recognizable categories, and generics emphasize important (i.e., characteristic, typical, or striking) features of a kind. Since generics are generalizations about kinds that express qualities that are either constitutive of the kind (birds fly), or are typical of the kind and represented by the majority or 


\section{Aleksandra Kowalewska-Buraczewska}

minority of its members (tigers have stripes, ducks lay eggs), or statistically regular (cars have radios), or striking and possessed by a certain proportion of the kind, however small (raccoons transmit rabies), they are understood as carrying information about the way members of a given kind are or behave, but not about the way they ought to be or ought to behave. None of the above examples carries a normative meaning (*'birds ought to fly', *'raccoons ought to transmit rabies'); instead, they put forward important knowledge about dispositional properties of the whole kind that are expected to be shared by particular instances of the kind.

Generics of the form $K$ s are $F$ (tigers have stripes, birds fly, ducks lay eggs), and $a K$ is $F$ statements (a tiger is ferocious) normally express the fact that there is a connection between the Ks (members of a kind) and $\mathrm{F}$ (feature), and that $\mathrm{F}$ is true about Ks by virtue of what it is to be a K. Leslie (2015, p. 244) claimed that, contrary to quantified statements, generics are extremely difficult to discuss truth-conditionally, e.g. mosquitoes carry the West Nile virus is true while books are paperbacks is not, even though in the former the property in question can be attributed to less than half of instances of the kind, and in the latter the property is attributed to the majority of instances, or ducks lay eggs is true despite the fact that eggs are laid only by female ducks, constituting less than a half of the whole population of ducks; however, as she points out in her later work, this does not mean that ducks are female is also true despite being based on the same logic (Leslie, 2017). The conceptual content of generics is acceptable as true even when speakers have sufficient background knowledge about exceptions. As might be seen from the above examples, generic statements can fall into two classes: class 1 embraces generics based on a property $\mathrm{F}$ that is an aspect of being a kind K, or an "essence" of being K (e.g. birds fly, tigers have stripes), and class 2 is made up of generics based on a property $\mathrm{F}$ that can be expected to be possessed by the instances of a kind $\mathrm{K}$, but not by virtue of them being a $\mathrm{K}$ (e.g. cars have radios, mosquitoes carry the West Nile virus). Following the work of Prasada and Knobe (2011), and Knobe et al. (2013), Leslie (2015) proposed another category of generic statements: normative generics (e.g. boys don't cry).

\subsection{Normative generics}

It was established in previous research by Prasada et al. (2013) $)^{10}$ that a prototypical linguistic form of generics in English is bare plural, except for principled generics that accept either form ${ }^{11}$. In this respect, normative generics structurally resemble principled generics (boys don't cry, a woman puts family before career). Conceptually, on the other hand, normative gener- 
ics show a certain affinity with principled generics in presuming that a feature $\mathrm{F}$ is expected to be prevalent, but is not essential for Ks to be Ks. The most important difference between principled and normative generics is that principled generics feature an average, while normative generics postulate an ideal standard. This means that in descriptive generics, Ks may be in accord with a typical norm but at the same time deviate from an ideal.

\section{Theoretical model for empirical study of normative constructions}

In what follows, the conceptual and linguistic complexity of normative generics is synthesized to construct a compact model for the linguistic study of normative constructions:

1. In general, generics are (unlike quantified statements) hard to describe truth-conditionally. That means that generic names do not accept all predicates that are true about them $(*$ books are paperbacks vs. pit bulls maul children);

2. Generics about natural kinds (e.g. artifacts or animals) do not have a normative dimension that is attributable only to social kinds (*tigers ought to have stripes vs. a woman ought to be submissive);

3. Not all social kinds allow normative interpretation. Normative senses are carried only by dual character concepts (Knobe et al. 2013) - i.e. such social kinds that represent concepts allowing descriptive and normative interpretation (e.g. "an acquaintance" vs. "a mother");

4. Dual conception characterizes only those social kinds that are connoted with being salient, culturally important, or charged (Knobe et al., 2013; Leslie, 2015). The ideal of a kind is determined by primary social roles attributed to such social kind, along with a property or properties necessary for members of this kind to successfully complete their primary social role (e.g. "a woman puts family before career", "boys don't cry"). Primary social roles are culture-specific and may be time-biased;

5. Being associated with an ideal is not a sufficient condition for a kind to have a dual conceptual character. The difference between dual and non-dual concepts lies in the fact that in the latter case, the social role attributed to them is the same as a specification of what it is to fulfill this role in a descriptive sense. Dual conception is characterized by the fact that a social role may be successfully served by an individual who does not satisfy the descriptive criteria of membership (e.g. the uses of gender terms in she truly has balls, or John is a perfect mother $)^{12}$. 


\section{Aleksandra Kowalewska-Buraczewska}

6. There is a distinction between normative generics and normativelyloaded predicates. An utterance can only be understood as normativelyloaded if the subject position is filled by a dual-character term $\mathrm{K}$, and the predicate assigns to it a quality $\mathrm{F}$ that is desired for a $\mathrm{K}$ to meet the ideal standard for a "real" or "true" $\mathrm{K}$; the implied normative meaning results from the underlying normative generic "Ks are F" whose normative force is "Ks ought to be $F$ and a $K$ that is not $F$ is not a real K". For example, in a situation in which a woman appears brave, she is likely to be described as "having balls". On the other hand, he's got balls uttered in a similar situation will also be naturally interpreted as 'he is brave'. In descriptive terms, the former utterance is false and the latter is true, since balls is a colloquial term for testicles (an essential physical and psychological attribute of masculinity), and it is impossible for a female to have them. In normative interpretation, both statements are true, as the intended normative reading is captured by appealing to the normative generic men have balls, which gets its normative import by way of its constitutive DCC and the underlying claim that it is a man's distinctive role to be brave, assertive and take charge. In the context of real men have balls, it appears that a man who does not possess such properties is not a real man. By implicit contrast, a woman said to have balls is understood as having the "mannish" property in question and so takes on mannish characteristics. Consequently, if a dual character term (e.g. your daughter meaning 'a girl' in "Your daughter's really got balls!"13) is present in a particular predication, it will have a normatively loaded semantic reading;

7. According to Leslie's claim, DCCs are polysemous items ${ }^{14}$, with one sense accommodating descriptive criteria of membership of a kind, and the other denoting the normatively loaded ideal;

8. The distinction between social kinds and social roles may promote confusion, as both concepts seem to overlap. Social kinds are not synonymous with social role terms that are used mostly in the sense of (social) function $^{15}$. Moreover, while such terms as artist, scientist, or friend are salient in terms of a norm or ideal that applies to their respective social kind by virtue of its societal role (the commitment factor) ${ }^{16}$, normative readings of gender terms operate in a different way:

a. If a scientist's role is to put truth above personal advancement, then Jack is not a scientist (context: Jack is a professional physicist who has been falsifying the results and faking his research);

b. Jack is a highly skilled scientist, but he has not been devoted to fulfilling his primary societal role of a scientist; 
c. If to be strong, take charge and lead, to be powerful and assertive is a man's role, then Hillary Clinton is a man (context: "Hillary Clinton is the only man in Obama's administration"17);

d. Hillary Clinton is biologically a woman, but she has not been devoted to fulfill her primary societal role of a woman.

Points (c) and (d) suggest that a woman who exhibits qualities typical of the distinctive role attributed to a man fails to fulfill or be committed to her primary role of a woman (being gentle, submissive, passive, and accommodating). This may lead to the conclusion that gender roles have a different conceptual structure, as they are key components of the cultural and social constructs of masculinity and femininity, manhood and womanhood, as well as motherhood and childhood. These roles are central to the construction of social reality ${ }^{18}$;

9. From a pragmatic perspective, an interesting question about normative generics is arguably not what they mean, but how and what for they are used. Due to their "hortatory" force, they naturally serve to advise, admonish, encourage, discourage, or rebuke (Leslie, forthcoming). Boys don't cry, for example, is descriptively false (obviously there are boys who cry), but in its normative reading it encourages holding back the expression of emotions. This may explain why normative generics are so effective in reinforcing social norms ${ }^{19}$.

\section{Conclusion}

The paper addresses a few problems that are vital to the study of normative generics and normatively loaded constructions: the question of social kind, the question of normality, the question of normativity, and the question of generic predication and dual conception. These problems must be addressed in order to develop an efficient theoretical model for empirical research into generics expressing norms of womanhood, femininity, manhood and masculinity, and normatively shifted predications that invoke these norms. While the author has managed to collect the most fundamental claims, the following issues still require further analytical work:

1. Firstly, there seems to be terminological confusion regarding social roles and social functions attributed to social kinds;

2. Secondly, there is a puzzling topic of the conditionality of social norms conveyed in generics, which means that the normative force may depend on culture and time (the "normative gradient" can be seen from the response to diverse normatively loaded utterances appealing to normative generics, but 


\section{Aleksandra Kowalewska-Buraczewska}

it may as well arise from different sensitivities to the same norm depending on different situational or cultural contexts; see Gaymard, 2016);

3. Thirdly, there is a need for empirical research into the persuasive force of different normatively shifted constructions in a situational context (e.g. persuading a boy to stop crying over a scratched knee: hey, it's all right/don't cry/don't cry like a girl/boys don't cry/be a man, etc.);

4. Fourthly, there are certain context-sensitive constructions questioning normative criteria of membership of a kind (e.g. you are no scientist, what kind of mother are you) that arguably need a deepened contrastive analysis, particularly in the quest for some universal normatively loaded constructions.

\section{Funding}

The project is financed from the grant received from the Polish Ministry of Science and Higher Education under the Regional Initiative of Excellence programme for the years 2019-2022, project number 009/RID/2018/19, the amount of funding 8791222,00 zloty.

\section{N O T E S}

${ }^{1}$ Cf. Cialdini \& Goldstein, 2004.

2 Natural kinds, as opposed to human (social) kinds, correspond to naturally existing divisions in nature (i.e. insect or metal). Firstly, human kinds are influenced by human action and social force and are min-dependent. Secondly, according to Hacking (1999), social kinds are subject to "looping effect". This means that once a practice or phenomenon is identified, those who engage or are involved in it may alter their behaviour and, consequently, alter the nature of the phenomenon or practice in question. Then, it "loops back" to change our beliefs about it, which in turn affects our behaviour and, in effect, that practice or phenomenon, and so on. Thirdly, as proposed by Searle (1995), social kinds are "ontologically subjective" as they depend on the very existence of human attitudes towards them. Finally, it is only social kinds that have normative dimension and are shaped by our value judgments and ideological stances (see Khalidi, 2013).

3 https://www.merriam-webster.com/dictionary/normal

4 https://www.merriam-webster.com/dictionary/normal

${ }^{5}$ Haslanger's research links philosophy of language with social and political issues concerning gender, race, and the family.

${ }^{6}$ Haslanger (2014) notes that under normal conditions does not mean 'under the most common conditions'.

7 Cf. Nickel, 2008. Nickel claims that generics are existential quantifications over ways of being normal in a determinable respect. Respects are dimensions within which one or more value is normal for a kind and others are abnormal. Reproductive method is one respect of being normal in that there are different ways to reproduce - internal gestation and live birth, egg-laying, etc. - and different species have different normal ways of giving birth. Therefore, ducks lay eggs means 'there is a way of being a normal duck with respect to reproduction and that way is to lay eggs'. 
8 Cf. Carlson \& Pelletier, 1995; Carlson, 2005; Greenberg, 2003; Nickel, 2016, Prasada \& Dillingham, 2005, and, for an overview of this complex phenomenon, see Krifka et al., 1995; Leslie, 2012.

9 See Leslie's research on generics and the cognitive mechanism responsible for the acquisition, production and comprehension of inductive generalizations. This article draws heavily on Leslie's latest works concerning the relation between generics (especially normative) and social prejudice and stereotyping (Leslie, 2014, 2015, 2017).

10 See also Cohen, 2005.

11 Principled generics involve features that are expected to be found in most instances of the kind by virtue of them being members of this kind, or at least are expected to be highly prevalent (see Prasada, Khemlani, Leslie \& Glucksberg, 2009; Prasada \& Dillingham, 2009). A detailed account of types of connections and respective types of generics as proposed by Prasada et al. and Leslie is given by Karczewski (2016).

12 Knobe et al. (2013) explain DCCs discussing the terms scientist and second cousin: one may believe a scientist who falsifies data and cares only about his or her personal advancement is not a true scientist, and consider a postal worker who uses an experimental method in the search for truth to be a true scientist, although the former is a scientist in the descriptive sense but fails to meet the normative criteria of being a scientist understood as 'a person who puts truth above personal advancement'. It might seem that there is not a corresponding ideal as regards the role of a second cousin or, say, bus driver. However, such "weak" terms may become "strong", i.e. possessing a normative sense provided there is an explicit discourse context where they represent the commitment to the idealized basic function associated with their role (i.e. Jack is a true bus driver. He always prioritizes safety but at the same time does his best to ensure students are not late for classes). The difference between "strong" and "weak" terms seems to be that terms such as scientist have a default basic function, while terms such as bus driver are highly context-sensitive. Cf. Del Pinal and Reuter (2016) and their experimental study in which they presented the participants with background information that asserted either the high-skill or the high-devotion of protagonists, and then analysed acceptability ratings of true-modifications.

13 The example taken from "It's not a Compliment to Say a Courageous Girl 'Has Balls"' by Meredith Gordon.

14 This concerns lack of agreement as to whether normative reading of certain generics is a question of semantics and lexical polysemy, or pragmatics and conversational implicature. Since both Leslie and Haslanger are involved in research projects spanning social cognition, philosophy of language, linguistics and psychology, their projects overlap (as is the case of normative generics), but quite naturally, there are several points where they stand in different positions. While Leslie expounds on normative generics in terms of polysemy and dual conception (Leslie, 2014, 2015), Haslanger gives justifiable arguments that normative senses are grounded in pragmatics and are a matter of conversational implicature (Haslanger, 2014). However, in her forthcoming article (Leslie, forthcoming), she juxtaposes these two stands, convincingly supporting her claim by the fact that a speech community can systematically use such terms as DCCs to communicate two meanings (i.e. descriptive/normative). Another argument in favour of the polysemous character of the items in question is liberal use of generics (normative generics included) in parentchild communication. In her previous research Leslie showed that generics can be used by two-year-olds, and despite the fact that there have not been empirical results concerning the comprehension of normatives by pre-schoolers, "liberal use of normative generics on behalf of parents is often an indication of competence on behalf of children" (Leslie, forthcoming). In addition, young children undoubtedly "tend to show a lag between appreciating semantic meaning and understanding implicatures" (Leslie, forthcoming), and they seem to grasp the intended meaning of normatives such as boys don't cry before they 


\section{Aleksandra Kowalewska-Buraczewska}

master pragmatic complexities of implicature. Further, a pragmatic account of normative generics divides the two senses, proposing that the normative generic has an underlying logical form that differs radically from its surface form (cf. Cohen, 2001; Carlson 1995), or requires assessing the truth or falsity of descriptive generics to conversationally reinterpret them as being normatively loaded.

15 For an elaborate account of social roles and relations see Znaniecki (1965).

16 Del Pinal \& Reuter, 2016.

17 Leslie, 2015.

18 Znaniecki, 1965; Searle, 1995, 2010; Haslanger, 2014.

19 And most probably social stereotypes.

\section{R E F E R E N C E S}

Bicchieri, C. (2006). The grammar of society. Cambridge: Cambridge University Press.

Bicchieri, C. (2016). Norms in the wild. How to diagnose, measure, and change social norms. Oxford: Oxford University Press.

Bicchieri, C., Muldoon, R., \& Sontuoso, A. (2018). Social Norms. In E. N. Zalta (Ed.), Stanford Encyclopedia of Philosophy. Retrieved from https://plato. stanford.edu/archives/win2018/entries/social-norms/.

Brennan, G., Eriksson, L., Goodin, R. E., \& Southwood, N. (2013). Explaining norms. Oxford: Oxford University Press.

Burton-Roberts, N. (1977). Generic sentences and analyticity. Studies in Language, 1, 155-196.

Carlson, G. N. (1995), Truth conditions of generic sentences: Two contrasting views. In G. N. Carlson \& F. J. Pelletier (Eds.), The generic book (pp. 224-238). Chicago: The University of Chicago Press.

Carlson, G. N. (2005), Generics, habituals and iteratives.In A. Barber (Ed.), The Encyclopedia of Language and Linguistics (2nd ed.). Amsterdam: Elsevier.

Cialdini, R. B., \& Goldstein, N. J. (2004). Social influence: Compliance and conformity. Annual Review of Psychology, 55(1), 591-62.

Cohen, A. (2001). On the generic use of indefinite singulars. Journal of Semantics, $18(3), 183-209$.

Cohen, A. (2005). More than bare existence: An implication of existential bare plurals. Journal of Semantics, 23, 381-400.

Del Pinal, G. \& Reuter, K. (2017). Dual character concepts in social cognition: Commitments and the normative dimension of conceptual representation. Cognitive Science, 41, 477-501. https://doi.org/10.1111/cogs.12456.

Gaymard, S. (2016). Conditionality and normative models in the field of social thinking. In: K.J. Fitzgerald (Ed.), Social Roles and Social Norms (pp. 111). New York: Nova Science Publishers, Inc. 
Gordon, M. It's not a compliment to say a courageous girl 'has balls'. Retrieved from https://www.momtastic.com/parenting/687185-not-compliment-to-say-a-co urageous-girl-balls /

Greenberg, Y. (2003). Manifestations of genericity. New York: Routledge.

Hacking, I. (1999). The social construction of what? Cambridge: Harvard University Press.

Haslanger, S. (2010). Resisting reality: Social construction and social critique. Oxford: Oxford University Press.

Haslanger, S. (2014). The normal, the natural and the good: Generics and ideology. Politica \& Societa, 3, 365-392.

Karczewski, D. (2016). Generyczność w języku i myśleniu. Studium kognitywne. Kraków, Poland: Universitas.

Knobe, J., \& Prasada, S. (2011). Dual character concepts. In Proceedings of the 33rd Annual Conference of the Cognitive Science Society (pp. 2965-2970). Boston, MA: Cognitive Science Society. Retrieved from https://pdfs.semanticscholar. org/f60b/2d25367883d3f238925297eb4a263269be77.pdf?_ga=2.46186663.12 2938527.1580650406-64654011.1580305066.

Knobe, J., Prasada, S., \& Newman, G. (2013). Dual character concepts and the normative dimension of conceptual representation. Cognition, 127, 242-257.

Khalidi, M. A. (2013). Kinds (natural kinds vs. human kinds). In B. Kaldis (Ed.), Encyclopedia of philosophy and the social sciences. Thousand Oaks, CA: Sage.

Krifka, M., Pelletier, F. J., Carlson, G., ter Meulen, A., Link, G., \& Chierchia, G. (1995). Genericity: An introduction. In G. N. Carlson \& F. J. Pelletier (Eds.), The generic book (pp. 1-125). Chicago: The University of Chicago Press.

Lawler, J. (1973). Studies in English generics (Doctoral dissertation). Reprinted in University of Michigan Papers in Linguistics 1(1). Retrieved from http:// www-personal.umich.edu/ jlawler/generics.html

Lavin, A. (2019). The explanatory link account of normality. Philosophy, 94(4), pp. 597-619. https://doi.org/10.1017/S0031819119000317.

Leslie, S.-J. (2008). Generics: Cognition and acquisition. Philosophical Review, $117(1), 1-49$.

Leslie, S.-J. (2012). Generics. In G. Russell \& D. Graff Fara (Eds.), Routledge companion to philosophy of language (pp. 355-366). London: Routledge.

Leslie, S.-J. (2015). Hillary Clinton is the only man in the Obama administration: Dual character concepts, generics, and gender. Analytic Philosophy, 56(2), 111-141.

Leslie, S.-J. (2017). The original sin of cognition: Fear, prejudice, and generalization. Journal of Philosophy, 114(8), 393-421.

Leslie, S.-J. (forthcoming). 'Real men': Polysemy or implicature. Analytic Philosophy. Retrieved from https://www.princeton.edu/ sjleslie/Real\%20Men $\% 20$ Polysemy\%20or\%20Implicature\%20final.pdf. 


\section{Aleksandra Kowalewska-Buraczewska}

Merriam-Webster dictionary. Retrieved from https://www.merriam-webster.com/ dictionary/

Nickel, B. (2008). Generics and the ways of normality. Linguistics and Philosophy, 33(6), 629-648.

Nickel, B. (2016). Between logic and the world: An integrated theory of generics. Oxford: Oxford University Press.

Olubiński, A. (1990). Rola społeczna a procesy socjalizacji i wychowania. Ruch Prawniczy, Ekonomiczny i Socjologiczny, 45(2), 267-284.

Petit, P. (1999). A theory of normal and ideal conditions. Philosophical Studies, 96, 21-44.

Prasada, S., Dillingham, E. M. (2006). Principled and statistical connections in common sense conception. Cognition, 99(1), 73-112.

Prasada, S., Dillingham, E. M. (2009). Representation of principled connections: A window onto the formal aspect of common sense conception. Cognitive Science, 33, 401-448.

Prasada, S. (2010). Conceptual representations and some forms of genericity. In F. J. Pelletier (Ed.), Kinds, things, and stuff: Mass terms and generics. New Directions in Cognitive Science. New York: Oxford University Press.

Prasada, S., Khemlani, S., Leslie, S.-J., \& Glucksberg, S. (2013). Conceptual distinctions amongst generics. Cognition, 126, 405-422.

Prentice, D. A., Miller, D. T. (1993). Pluralistic ignorance and alcohol use on campus: Some consequences of misperceiving the social norm. Journal of Personality and Social Psychology, 64, 243-256.

Searle, J. R. (1995). The construction of social reality. Penguin Books.

Searle, J. R. (2010). Making the social world. The structure of human civilization. Oxford: Oxford University Press.

Znaniecki, F. (1965). Social relations and social roles. San Francisco: Chandler Publishing Company. 